\section{Estimating Consumers' Valuation of Organic and Cosmetically Damaged Apples}

\author{
Chengyan Yue ${ }^{1}$ and Helen H. Jensen \\ Department of Economics, 577 Heady Hall, Iowa State University, \\ Ames, IA 50010
}

\section{Daren S. Mueller \\ Department of Plant Pathology, Bessey Hall, Iowa State University, Ames, IA 50011}

\section{Gail R. Nonnecke \\ Department of Horticulture, Horticulture Hall, Iowa State University, Ames, IA 50011}

\author{
Douglas Bonnet \\ Department of Statistics, Snedecor Hall, Iowa State University, \\ Ames, IA 50011 \\ Mark L. Gleason \\ Department of Plant Pathology, Bessey Hall, Iowa State University, \\ Ames, IA 50011
}

Additional index words. sooty blotch and flyspeck, consumer willingness to buy, fruit quality

\begin{abstract}
The sooty blotch and flyspeck (SBFS) disease complex causes cosmetic damage but does not affect the safety or eating quality of apples. Treatment for disease is more difficult and costly for organic producers, and consumers' willingness to pay for organic apples needs to be considered in growers' choice of production technologies. A mixed probit model was applied to survey data to evaluate consumers' willingness to buy apples. The results show consumers will pay a premium for organic production methods and for apples with low amounts of SBFS damage. Behavioral variables such as experience growing fruit significantly affect the willingness to buy apples of different damage levels. Consumers have limited tolerance of very blemished apples and trade off production technology attributes for cosmetic appearance. Better understanding of this tradeoff can improve organic producers' decisions about disease control.
\end{abstract}

Coherent risk management strategies are crucial to making good economic and production decisions for apple growers. Apple growers face a complex risk environment that includes single- and multiple-year risks from insect pests, diseases, weeds, vertebrate pests, nutritional imbalances, and volatile apple prices. Earles et al. (1999) hypothesized that decreased profit margins would force many apple growers out of business, and others would consider shifting to value-added activities, including organic production, to gain a price premium for their fruit. Organic apples have become popular in farmers' markets as well as in grocery stores (Kremen et al., 2004). Compared with conventionally grown fruit, the price of fresh organic apples may range from $\$ 3$ to $\$ 15$ more per $18.2-\mathrm{kg}$ (40-pound) box higher (or $\$ 0.165$ to $\$ 0.66$ per kilogram) (Granatstein and Kirby, 2002). At

Received for publication 29 Nov. 2006. Accepted for publication $10 \mathrm{Feb} .2007$.

${ }^{1}$ To whom reprint requests should be addressed; e-mail yuechy@iastate.edu.
The threat of economic losses from SBFS is the main reason that apple growers in the northeastern quarter of the United States apply four to eight fungicide sprays from shortly after petal fall until harvest. Darkcolored colonies of the SBFS fungi blemish the fruit cuticle, especially in wet growing seasons. Such defects, although primarily cosmetic and with no effect on fresh eating quality, result in culled fruit and reduce the value of an apple crop by up to $90 \%$. Blemished fruit are downgraded from freshmarket to cider grade and become desiccated during storage (Williamson and Sutton, 2000). SBFS is controlled by fungicides during the growing season; if disease is not too severe, the damage may be removed from harvested apples by washing and brushing (Batzer et al., 2002).

Organic apple producers face additional challenges in addressing pest control. For example, organic producers must control weeds and monitor and respond rapidly to harmful diseases and insects but are constrained to use a more limited set of approved products and methods for weed management and pest control. Many organic methods are more costly and somewhat less effective than methods used in commercial production (Reganold et al., 2001). Consequently, organic apples may not be as attractive in appearance as conventionally grown apples.

Although the additional income from the higher price of an organic product may have appeal, higher costs and risks in production as well as consumers' discounting of inferior appearance may deter apple producers from transitioning from conventional to organic production. These conditions leave open the questions of the extent to which consumers discount apples with cosmetic damage and to what extent the discount response is modified by organic production methods.

Some studies consider how appearance affects consumers' preference for a particular food product. The characteristics include intrinsic attributes of color, texture, and other visible differences (see Acebron and Dopico, 2000, for beef; Campbell et al., 2004, for Satsuma mandarins; and Kelly et al., 2001, for edible flowers). Bunn et al. (1990) analyzed survey data from a supermarket and found a low acceptance rate of cosmetically damaged oranges. The acceptance rate increased substantially after consumers were informed that few pesticide sprays were used to produce the oranges.

Most previous studies related to organic foods focus on consumers' preference for organic attributes by assuming equal cosmetic appearance (Blend and van Ravenswaay, 1999; Larue et al., 2004; Loureiro, et al., 2001). A few studies do consider the effect of cosmetic problems and in general they find that consumers discount cosmetic damage (Baker, 1999; Roosen et al., 1998; Thompson and Kidwell, 1998). Thompson and Kidwell (1998) estimated the choice between organic and conventional fruits and vegetables (including apples) with consideration of the cosmetic defects. They found that the 
cosmetic defects that can frequently be observed such as broken skin, bruises, and degree of waxiness of apples, and flowering bud clusters in broccoli, affected consumers' choice between organic and conventional produce and found that the more cosmetic defects in organic produce, the less likely shoppers were to buy the organic produce. Baker (1999) found consumers in a market segment with strong preference for "perfect produce" (produce without damage) had higher income levels. For other identified consumer groups, cosmetic damage was less of a factor in their consumer choices. Roosen et al. (1998) found that consumers were willing to pay less for apples when there was cosmetic damage. Although cosmetic damage reduced the probability of purchase, it had little effect on the magnitude of the premium for "low pesticide input" apples. In summary, the previous studies suggest that cosmetic appearance in fruit is an important attribute in the consumer's purchase decision, at least for some consumers; however, the effect of production method and tradeoff between appearance and production method is less well known.

Our study addresses explicitly the tradeoff between cosmetic appearance and organic production methods to provide estimates of consumers' willingness to pay (WTP) for organic apples in fresh fruit markets. Unlike previous studies, we use a mixed probit model to analyze consumers' willingness to buy apples with cosmetic damage that allows us to treat two factors simultaneously: production method and cosmetic appearance. We analyze how the two factors affect the willingness to purchase apples. We also analyze the effect of variables related to consumer behavior on the estimate of willingness to purchase the apples.

\section{Materials and Methods}

Consumers' willingness to buy apples with different amounts of cosmetic damage incited by SBFS is expressed as two categories, willing to buy and unwilling to buy. The two categories are used to measure the corresponding latent uses or degree of satisfaction consumers get from their purchase. Because the dependent variables are categorical instead of quantitative, we use a mixed probit model to estimate the probability of a consumer's willingness to buy the apples. In contrast to a general probit model, the mixed probit model includes a random effect. Because each participant was asked to evaluate multiple apples, there is correlation between responses on apples evaluated by the same person. The random individual effect is introduced to capture this correlation.

The consumers' satisfaction derived from the consumption of apples relies on measurable factors, including the level of cosmetic damage (or appearance), the production method used (organic or conventional), and consumers' characteristics. The characteristics include the consumer's experience in growing fruits and vegetables, experience in purchasing organic fruits and vegetables, and household demographics (the presence of young children in the household). In addition to the coefficients related to these parameters, a random effect is included that is designed to capture the correlation between the evaluations done by the same respondent. This random effect is assumed to follow a normal distribution with mean zero and certain variance to be estimated.

The satisfaction that consumers get from the apples cannot be observed. What we observe is the consumer's willingness to buy apples. In a survey that asks questions about the respondent's opinion, the response is dependent on these measurable factors. Here, respondents are not asked to respond with a degree of satisfaction directly. Instead, the respondent is given only a set number of possible answers (say five) to the following question: would they be very unwilling to buy, somewhat willing to buy; neutral, somewhat unwilling to buy, or very unwilling to buy. Consumers choose the response that most closely represents their own feelings. To simplify the model, we group the answers into two categories: willing to buy (the first three categories) and unwilling to buy (the last two categories). (We also classified a "neutral" group as "willing to buy" and got similar results.)

The maximum likelihood estimation method is used to estimate the coefficients. The program is compiled in $R$.

This study focuses on one type of damage to apples: cosmetic surface blotches incited by SBFS. Consumers evaluated color photographs of six 'Golden Delicious' apples presented on one sheet of paper. The apple size in the photograph was similar to the actual size of an apple. The first apple, identified as apple U, had no blotches. This apple was considered to be "perfect" and was used to make comparisons for other apples. The price of conventional apple $\mathrm{U}$ is used as the anchor price, which was 75 cents per pound at the orchards where the survey was taken. The second apple, identified as V, had blotches that covered $1 \%$ of its surface. The third one (W) had 3\% blotch coverage; and the remaining three apples, identified as $\mathrm{X}, \mathrm{Y}$, and $\mathrm{Z}$, had blotch coverage of $5 \%, 7 \%$, and $9 \%$, respectively. (To see if there is ordering effect, we conducted another survey using both the ordered and unordered blemished apple pictures. We found the order of the apples according to blemish levels in the picture had no significant effect on the estimation results.) Figure 1 shows the apple pictures presented to the survey participants.

To concentrate only on the problem of cosmetic damage, the interviewer stated at the beginning of the questionnaire that the surface blotches are incited by SBFS fungi, that the fungi do not harm humans or the taste of apples, and that the damage is strictly cosmetic. The interviewees were asked to look at the photograph of the six apples and then decide how willing they would be to buy apples V through Z. They had five choices: very willing, somewhat willing, neutral, somewhat unwilling, or unwilling.

After making the choice of willingness to buy for each of the apples pictured, the consumer was asked to answer several additional questions concerning frequency of apple purchase, previous gardening or purchase experience, and preferences for local production in their purchase decision. To test whether individuals are more tolerant of cosmetic damages for organic than for conventional apples, and to obtain an indication of the discount associated with the damage, additional questions presented on some of

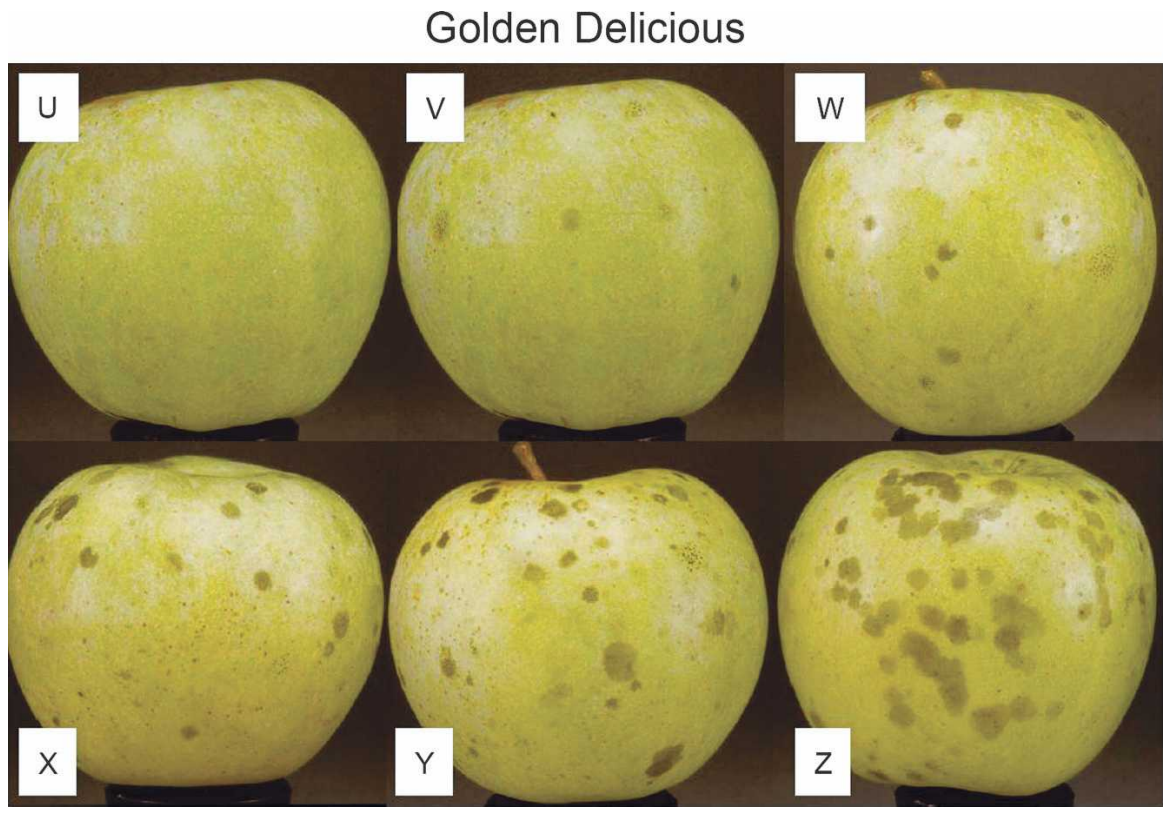

Fig. 1. Apple photograph presented to survey participants depicting $0 \%(\mathbf{U}), 1 \%(\mathbf{V}), 3 \%(\mathbf{W}), 5 \%(\mathbf{X})$, $7 \%(\mathbf{Y})$, and $9 \%(\mathbf{Z})$ coverage of cosmetic damage. 
the questionnaires asked consumers to indicate their willingness to purchase the apples if there were a 15-cent discount per pound (Discount) (The 15-cent discount was chosen as the approximate premium for organic 'Golden Delicious' apples in 2004. The amount is about the same as the estimation results obtained by Wang (2005) on the premium for organic 'Golden Delicious' apples in 2003 and 2004.) based on the 75 -cent anchor price and if the apple were organic (Organic). The interviewees received one of four types of questionnaires: conventional nondiscounted questionnaire; conventional discounted questionnaire; organic nondiscounted questionnaire; and organic discounted questionnaire. Each interviewee was asked only to finish one type of questionnaire so as to ensure the survey results would be independent across the organic and discount factors.

The survey was conducted during regional apple festivals at two orchards in a Midwestern state in October 2004. Individuals entering the festival site were selected randomly. To collect a representative sample, this survey was conducted from $1000 \mathrm{HR}$ to $1700 \mathrm{HR}$ for more than $1 \mathrm{~d}$ during the festivals in each of the two orchards.

In total, 471 people were surveyed, of which 454 responded to all the questions. Among the 454 participants, 104 of them responded to the conventional apple, nondiscounted questionnaire; 117 of them responded to the conventional apple, discounted questionnaire; 108 responded to the organic apple, nondiscounted questionnaire; and 125 responded to the organic apple, discounted questionnaire.

Data analysis. The empirical specification of the preference function underlying the mixed probit model makes reference to both price (the 15-cent discount) and production technology (organically produced or conventionally produced). The preference function is formulated as follows:

$$
\begin{aligned}
\mathrm{U}_{\mathrm{ij}}= & \alpha_{j}+\beta_{1} \text { Distance }_{i}+\beta_{2} \text { FreqBuy }_{i}+ \\
& \beta_{3} \text { Appleaweek }_{i}+\beta_{4} \text { ExperGrow }_{i}+ \\
& \beta_{5} \text { BoughtOrganic }_{i}+\beta_{6} \text { Local }_{i}+ \\
& \beta_{7} \text { Children }_{i}+\beta_{8} \text { Organic }_{i}+ \\
& \beta_{9} \text { Discount }_{i}+\beta_{10} \text { Appleaweek }_{i} \times \\
& \text { Children }_{i}+\beta_{11} \text { ExperGrow }_{i} \times \\
& \text { Local }_{\mathrm{i}}+\eta_{\mathrm{i}}+\varepsilon_{\mathrm{ij}}
\end{aligned}
$$

where $i=1, \ldots 454 ; j=V, W, X, Y, Z$. The term $U_{i j}$ is the latent unobservable use level for consumer $i$ by consuming apple $j$. The variables are defined in Table 1. The observed apple rating (degree of willingness to buy) reflects this latent use.

The variable "Organic" indicates the production technology-organically produced or conventionally produced (Thompson and Kidwell, 1998). The variable "Discount" indicates the price premium for an apple with blotches compared with a "perfect"-appearing apple. Specifically, Organic is coded as $(1,0)$, where 1 represents organically produced and 0 represents conventionally produced; and Discount is coded as $(0,15)$, where 15 represents 15 cents per pound discount and 0 represents no discount. A mixed probit model based on the empirical representation of the latent nonobservable preference function is estimated using the maximum likelihood method.

\section{Results and Discussion}

Summary statistics and descriptions of the questions are presented in Table 1. Nearly one-third $(31 \%)$ of the respondents bought apples once a week (FreqBuy); two-thirds $(67 \%)$ of them have grown fruit or vegetables in a garden or orchard (ExperGrow); $40 \%$ of the respondents have bought organic fruits or vegetables (BoughtOrganic); $69 \%$ of them thought locally grown is important or very important in their purchasing decision
(Local); and $47 \%$ of them had young children at home (Children). On average, consumers purchased five apples a week from all sources.

Table 2 shows the proportion of consumers who are willing to buy each type of apples. As expected, as blotch coverage level increases, the proportion of consumers who are willing to buy the particular type of cosmetically damaged apples decreases. The proportion of consumers who are willing to buy organic cosmetically damaged apples is larger than (or equal to) that of consumers who are willing to buy conventional cosmetically damaged apples holding blotch coverage level and discount level constant. The proportion of consumers who are willing to buy cosmetically damaged apples with a 15cent discount is larger than (or equal to) that of consumers who are willing to buy cosmetically damaged apples without any discount holding blotch coverage level and production method constant.

Estimation results are presented in Table 3. First, we note that the value for $\hat{\sigma}_{\eta}$ is quite large and is statistically significant, indicating that the correlation among the evaluations of different cosmetically damaged apples by the same person is significant, and this aspect of the survey cannot be ignored. Ignoring the correlation could lead to the wrong model specification and estimation results.

The results in Table 3 show that previous experience, preferences, and demographics all affect the willingness to purchase apples. The variable "Appleaweek" - number of apples bought from all sources in a weekmeasures whether the person is a regular apple consumer. The probability of being willing to buy a particular apple is expected to be larger if a person is a regular apple consumer as compared with the willingness of a person who is not a regular consumer. As expected, being a more frequent apple consumer has a positive effect on willingness to buy cosmetically damaged apples.

Table 1. Summary statistics for questions on respondent characteristics $(n=454)$.

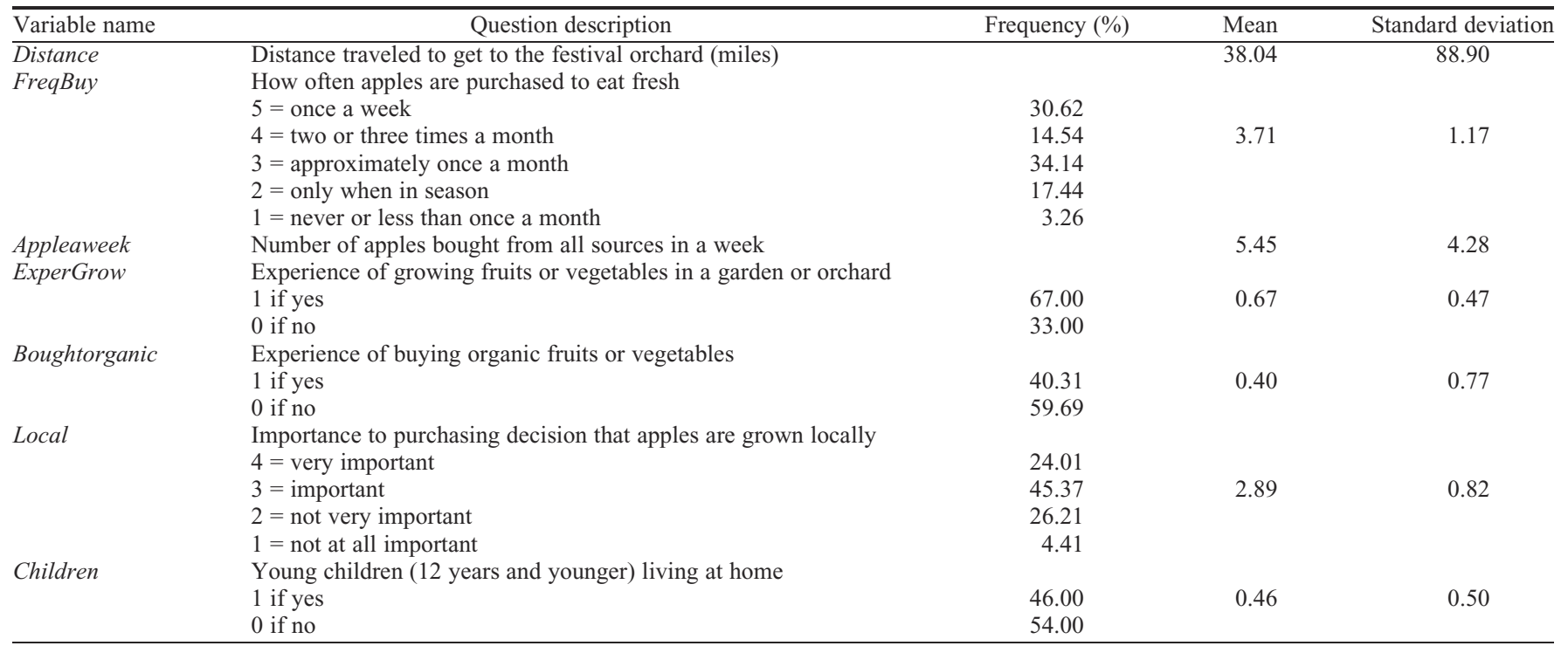


Table 2. Percentage of consumers who are willing to buy cosmetically damaged apples with and without a discount in price.

\begin{tabular}{|c|c|c|c|c|}
\hline \multirow{2}{*}{$\begin{array}{l}\text { Percent damage of } \\
\text { apple and letter code }\end{array}$} & \multicolumn{2}{|c|}{ Conventional apples } & \multicolumn{2}{|c|}{ Organic apples } \\
\hline & $\overline{\text { No discount }(104)^{z}}$ & Discount $(117)^{z}$ & $\overline{\text { No discount }(108)^{\mathrm{z}}}$ & Discount (125) \\
\hline$\frac{11}{1 \%(V)}$ & $82 \%$ & $87 \%$ & $88 \%$ & $92 \%$ \\
\hline $3 \%(\mathrm{~W})$ & $55 \%$ & $68 \%$ & $58 \%$ & $76 \%$ \\
\hline $5 \%(\mathrm{X})$ & $34 \%$ & $44 \%$ & $37 \%$ & $44 \%$ \\
\hline $7 \%(\mathrm{Y})$ & $17 \%$ & $19 \%$ & $19 \%$ & $22 \%$ \\
\hline $9 \%(Z)$ & $11 \%$ & $11 \%$ & $11 \%$ & $15 \%$ \\
\hline
\end{tabular}

${ }^{\mathrm{z}}$ Number of respondents for each of four types of surveys.
The variable "Children" is a proxy for the size of the household. It has a significant positive effect on the probability of the willingness to buy cosmetically damaged apples, which implies a person with a larger household is more likely to buy apples (Roosen et al., 1998). There is a significant negative interaction effect for Appleaweek and Children. Because the variable "Appleaweek" is the number of apples bought from all sources in a week, the marginal effect of "Appleaweek" on the probability of buying cosmetically damaged apples is discounted by the household size. For example, the person in a household with four people who buy seven apples a week is not as regular an apple consumer as the person in a household with only one person who buys the same number of apples in a week.

The variable "ExperGrow" is also expected to affect the probability of willingness to buy in a positive way. The positive and those who have grown fruits and vegetables tend to like cosmetically damaged apples more and would be more willing to buy apples with blemishes. The variable "Local" has a significant positive effect on the probability of being willing to buy cosmetically damaged apples. People who place greater importance on locally grown production also tolerate apples with more blemishes, as expected. However, there is also an interaction effect of "ExperGrow" and "Local" on the probability of buying cosmetically damaged apples.

Table 3. Estimated coefficients for consumers' willingness to buy apples based on a mixed probit model $(n=454)$.

\begin{tabular}{lcc}
\hline Variables $^{z}$ & $\begin{array}{c}\text { Estimated } \\
\text { coefficients }\end{array}$ & $\begin{array}{c}\text { Standard } \\
\text { error }\end{array}$ \\
\hline Distance & 0.001 & 0.002 \\
FreqBuy & -0.21 & 0.14 \\
Appleaweek & $0.35^{* * *}$ & 0.11 \\
ExperGrow & $1.59^{* * *}$ & 0.60 \\
Boughtorganic & -0.13 & 0.21 \\
Local & $1.29 * * *$ & 0.38 \\
Children & $1.66^{* * *}$ & 0.46 \\
Organic & $0.66^{* *}$ & 0.31 \\
Discount & $0.06^{* * *}$ & 0.02 \\
Appleaweek* Children & $-0.19^{* * *}$ & 0.10 \\
ExperGrow ${ }^{*}$ Local & $-1.03^{* * *}$ & 0.12 \\
$\alpha_{W}$ & $-2.16^{* * *}$ & 0.13 \\
$\alpha_{X}$ & $-4.22^{* * *}$ & 0.14 \\
$\alpha_{Y}$ & $-6.55^{* * *}$ & 0.07 \\
$\alpha_{Z}$ & $-8.10^{* * *}$ & 0.28 \\
$\sigma_{\eta}$ & $3.26^{* * *}$ & 0.26 \\
\hline${ }^{2}$ See Table 1 for explanation of variables. \\
* $_{* * \text { Significant at the 1\% level; } * * \text { significant at the }}$ \\
5\% level.
\end{tabular}
statistically significant coefficient means that
The marginal effect of "Local" on preferences is

$$
\begin{aligned}
& \beta_{6}+\beta_{11} \text { ExperGrow }= \\
& 1.29-1.03 * \text { ExperGrow }
\end{aligned}
$$

when ExperGrow $=0$, the marginal effect of "Local" is 1.29; when ExperGrow = 1, the marginal effect of "Local" is 0.26 . This result indicates that consumers' attitudes toward local production affect their utility from consuming apples, but the effect of this attitude is larger for people who have never grown anything compared with those who have experience growing produce and fruit. This might be because the people who have experience with growing products know that there is not as large a quality difference between the locally produced fruits and nonlocally produced fruits as those who have no growing experience might think.

Results in Table 3 also show that the production technology - organic productionaffects the probability of being willing to buy apples in a positive direction and the effect is statistically significant. If an apple is produced organically, the consumer has a higher probability of being willing to buy it. The 15-cent discount has a positive and statistically significant effect on the probability of being willing to buy cosmetically damaged apples. With the presence of a 15-cent discount, the consumer is more willing to buy apples with varying degrees of cosmetic damage (as shown in Table 3 ).

Based on the estimated results in Table 3, it is possible to compute how much less consumers are willing to pay for apple $j$ com- pared with apple $\mathrm{V}$ (the apple with blotch coverage of $1 \%$, a level that is not highly visible or conspicuously discolored). For cosmetically damaged apples of type $j=\mathrm{W}, \mathrm{X}$, $\mathrm{Y}, \mathrm{Z}$ the unit is cents per pound. By calculation of the value $\alpha_{j} / \beta_{9}$, we obtain the result that the average consumer is willing to pay $\$ 0.36$ less for one pound of cosmetically damaged apples of type $\mathrm{W}, \$ 0.70$ less for one pound of cosmetically damaged apples of type X, $\$ 1.09$ less for one pound of cosmetically damaged apples of type $\mathrm{Y}$, and $\$ 1.35$ less for one pound of cosmetically damaged apples of type $\mathrm{Z}$ compared with cosmetically damaged apples of type $\mathrm{V}$ (the apple with least amount of cosmetic damage). Similarly, the ratio $\beta_{8} / \beta_{9}$, equivalent to $\$ 0.11$ per pound, provides an estimate of how much more consumers are willing to pay for organic apples versus conventional apples with the same spot coverage level. The premium of $\$ 0.11$ per pound is in the range of the results from earlier studies (Granatstein and Kirby, 2002).

Figure 1 indicates how much consumers are willing to pay for (organic) apples with $\$ 0.75$ as the price for conventional $\mathrm{V}$ apples (an apple produced by conventional methods and having $1 \%$ blotch coverage). Figure 2 shows that consumers' tolerance for blotches is quite limited even if the apple is organically produced. For example, in the case when consumers are willing to pay $\$ 0.75$ per pound for conventional apple $\mathrm{V}$, they are only willing to pay $\$ 0.59$ per pound for an organic apple with 3\% blotch level (apple W), a result that indicates that relatively low amounts of blotches are still "too many" even if the apple is organically produced. Consumers make a tradeoff between production method and cosmetic appearance.

We expected consumers to be more tolerant of cosmetically damaged apples if the fruit was produced organically. Our survey results show that organic production methods do significantly affect the consumers' willingness to buy cosmetically damaged apples; however, the resulting premium is relatively different blotch levels taking the value of small. In contrast, consumers are relatively

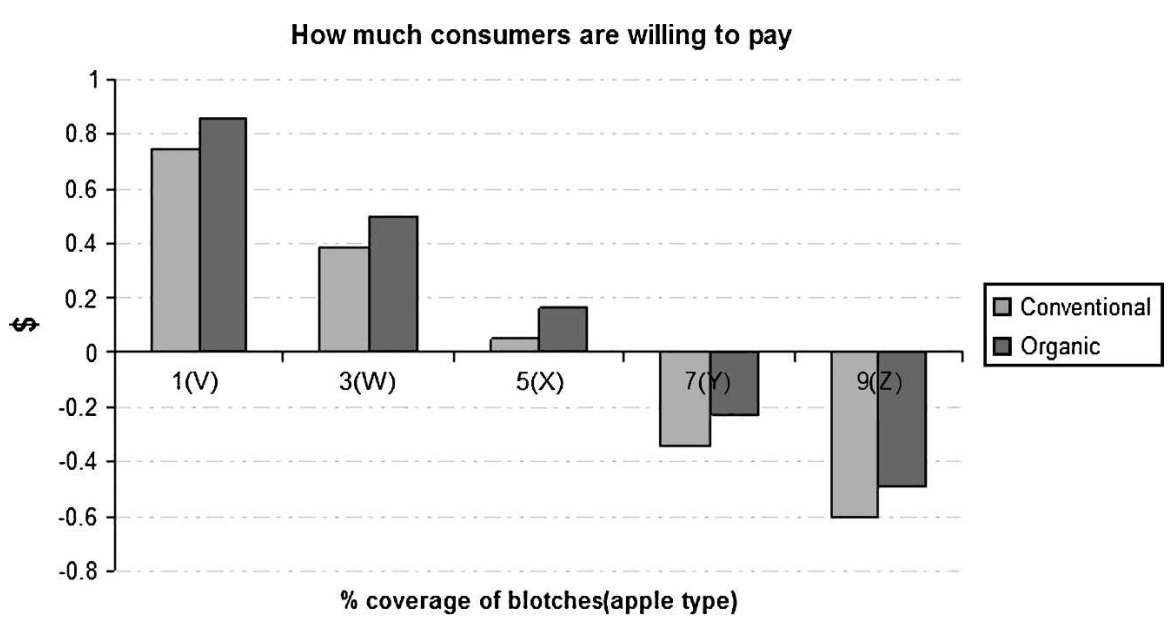

Fig. 2. Consumers' willingness to pay for apples with different percentage of cosmetic damage coverage $[1 \%(\mathrm{~V}), 3 \%(\mathrm{~W}), 5 \%(\mathrm{X}), 7 \%(\mathrm{Y})$, and $9 \%(\mathrm{Z})]$. 
more sensitive to the occurrence of cosmetic damage. One possible reason is that visual appearance is an intrinsic attribute that is "easy" to define because consumers only need to take a look at the apple to know the attribute. However, organic as an attribute is harder to define because it is a credence characteristic (Darby and Karni, 1973) and consumers cannot validate it either before or after purchase. Trading off an easy-to-define attribute for a hard-to-define attribute may explain the low WTP for the organic attribute.

One issue to consider is whether the survey results are representative of consumers in general (Mitchell and Carson, 1989). In our survey, the sample chosen - those who participate in autumn apple festivals - does not necessarily represent all those who would purchase apples, and in this regard, there is some bias in the sample selection. It is quite possible that the segment of the population interested in apple festivals and in purchasing local products is more tolerant of cosmetic damage on apples than the general applepurchasing population. At the same time, the public participating in local apple markets is an important market segment for organic apple producers. However, there may also be population choice bias. The two orchards are located in the center of a Midwestern state.

Based on the variable "Distance" the average driving distance was estimated to be 38 miles with a standard deviation of 89 miles. This result indicates that the population was drawn from the local and regional area. We thus view our sample respondents as representing a population of the central Midwest that would travel to local apple markets. These two apple festivals were selected randomly and the orchards sponsoring them do not produce organic apples. Therefore, although the participants may hold preferences toward fresh apples, these consumers are not predisposed to purchase organic apples. As for sample bias, the sample would not be representative of the total U.S. population but it is representative of consumers in the Midwestern area. Given the potential biases, the extrapolation of our findings to other populations should be made with caution. We interpret the findings relative to the population attending local and regional festivals and markets. A small percentage of the surveys $(4 \%)$ were categorized as invalid, mainly because of incomplete answers, and not used in the analysis. The literature (List and Gallet, 2001; Murphy et al., 2005) shows there is some hypothetical bias by using pictures instead of real products. Consumers often bid more in auctions using pictures than using real products. Despite the hypothetical bias, evidence from the earlier studies mentioned indicates that our contingent valuation gives a similar ranking and relationship between consumers' willingness to buy food products displayed in pictures to results with real food product. Hence, we expect that consumers' willingness to buy apples with different levels of cosmetic damage to be similar to the results obtained by using real products, although the absolute differences in willingness to pay for the different apples might be different.

\section{Conclusion}

Our survey of consumers in a local market setting shows that consumers make a tradeoff between production technology and cosmetic appearance of apples, although cosmetic damage weighs significantly in their decision. Consumers' tolerance of cosmetic damage on apples is limited. When there are "too many" blemishes on the surface of organic apples, consumers would rather buy conventional ones with better appearance, even if the spots are merely a cosmetic problem.

In addition, variables that reflect consumer attitudes and previous behaviors do affect the consumers' willingness to purchase the cosmetically damaged apples; experience of growing fruit or vegetables and whether being locally grown are important factors for the purchase decision.

The presence of cosmetic damage reduces the grade and market value of organic apples. At the same time, the cost of producing organic apples is likely to be higher than for producing apples by conventional growing methods. Organic production methods often require more management time and timely, frequent application of treatments in the eastern United States. The threat of losses is greater in the eastern United States because the pest complex is more diverse and weather is more disease-favorable than in the West (Earles et al., 1999; Ellis, 1997).

In the case of SBFS, the use of fungicides at the right production time would minimize significant loss resulting from cosmetic blemishes. Apples produced by organic production methods are estimated to cost $\approx 2.6$ to 3.3 cents per pound more than those produced by conventional methods assuming equal appearance in Washington State (Glover et al., 2002). As a result of different climate conditions, the additional cost may vary among regions or states. In general, there are many fewer summer sprays in the West compared with the eastern United States. The SBFS complex and other summer diseases like bitter pit need moisture, which is lacking in the West. So, one of the additional costs for growers in the eastern United States would be the cost of fungicide applications to control summer diseases. Our finding of an 11-cent premium that consumers are willing to pay for organic apples would be likely to cover this additional cost of organic production (2.6 to 3.3 cents per pound) in the western United States if the organic apples look as good as conventional ones. However, it is true that costs of organic production may be higher in the eastern United States as a result of the higher cost of spraying (Earles et al., 1999; Ellis, 1997). If costs were less than 11 cents per pound in the East, the premium would be sufficient to cover the additional costs of organic production. In addition, organic producers face higher production cost in the years with significant disease pressure, and the advantages of the premium may quickly dissipate. It is important to note that the respondents were informed that the cosmetic damage was benign and purely cosmetic. In market situations, the sellers would not have an opportunity to make such statement. By doing so, this result may give a conservative estimate of the consumers' discount of cosmetic damage on the (organic) apples.

The relatively low consumer acceptance of cosmetic damage to apples narrows the margin of error for organic growers and makes decision-making for organic growers challenging. Because of the limited consumer tolerance for cosmetic damage, apple producers must account for the tradeoff between production technology and cosmetic damage in their production decisions to ensure their profits. In addition to improved management, use of inputs, and preparation of apples for sale, there may also be some opportunities for improved marketing of cosmetically damaged apples at farmers' markets or grocery stores. Although we stated on the questionnaire that the apple damage was strictly cosmetic, consumers may have doubt about the fact and inferred problems with taste or storage. Additional consumer education and promotion through recipes and tips for use may improve the market for apples with reduced appearance.

\section{Literature Cited}

Acebron, L.B. and D.C. Dopico. 2000. The importance of intrinsic and extrinsic cues to expected and experienced quality: An empirical application for beef. Food Quality and Preference 11:229-238

Baker, G.A. 1999. Consumer preferences for food safety attributes in fresh apples: Market segments, consumer characteristics, and marketing opportunities. J. Agr. Resource Econ. 24:8097.

Batzer, J.C., M.L. Gleason, P.M. Dixon, and F.W. Nutter, Jr. 2002. Evaluation of post-harvest removal of sooty blotch and flyspeck on apples using sodium hypochlorite, hydrogen peroxide with peroxyacetic acid, and soap. Plant Dis. 86:13251332.

Blend, J.R. and E.O. van Ravenswaay. 1999. Measuring consumers' demand for ecolabeled apples. Amer. J. Agr. Econ. 81:1072-1077.

Bunn, D., L. Lynch, and R. Sommer. 1990. Consumer acceptance of cosmetically imperfect produce. J. Consum. Aff. 24:268-279.

Campbell, B.L., R.G. Nelson, R.C. Ebel, W.A Dozier, J.L. Adrian, and B.R. Hockema. 2004. Fruit quality characteristics that affect consumer preferences for satsuma mandarins. HortScience 39:1664-1669.

Darby, M.R. and E. Karni. 1973. Free competition and the optimal amount of fraud. J. Law Econ. 16:67-88.

Earles, R., G. Ames, R. Balasubramanyam, and H. Born. 1999. Organic and low-spray apple production. Appropriate Technology Transfers for Rural Areas (ATTRA).

Ellis, M.A. 1997. Disease management guidelines for organic apple production in Ohio. Ohio State University, Dept. of Plant Pathology.

Granatstein, D. and E. Kirby. 2002. Current trends in organic tree fruit production. CSANR Rpt. No. 4 May 2002. Ctr. Sustaining Agr. and Natural Resources, Wenatchee, WA. 
Glover, J., H. Hinman, J. Reganold, and P. Andrews. 2002. A cost of production analysis of conventional vs. integrated vs. organic apple production systems. Agr. Res. Ctr. Publ. XB1041, Washington State University.

Grove, G.G., K.C. Eastwell, A.L. Jones, and T.B. Sutton. 2003. Disease of apples. Chapter 18, p. 459-488. In: Ferree, D.C. and I.J. Warrington (eds.). Apples: Botany, production, and uses. CABI, Cambridge, MA

Jones, A.L. and H.S. Aldwinkle. 1990. Compendium of apple and pear diseases. Amer. Phytopathol. Soc., St. Paul, MN.

Jones, A.L. and T.B. Sutton. 1996. Diseases of tree fruits in the East. Publ. NCR 45, Michigan State University Ext., East Lansing.

Kelly, K.M., B.K. Behe, J.A. Biernbaum, and K.L. Poff. 2001. Consumer preference for edibleflower color, container size, and price. HortScience 36:801-804.

Kremen, A., C. Greene, and J. Hanson. 2004. Organic produce, price premiums, and ecolabeling in U.S. farmers' markets. Outlook Rpt. No. (VGS-301-01), Apr. 2004, ERS, USDA.
Larue, B., G.E. West, C. Gendron, and R. Lambert. 2004. Consumer response to functional foods produced by conventional, organic, or genetic manipulation. Agribusiness: Intl. J. 20:155-166.

List, J.A. and C.A. Gallet. 2001. What experimental protocol influence disparities between actual and hypothetical values? Environ. Resour. Econ. 20:241-254.

Loureiro, M.L., J.J. McCluskey, and R.C. Mittelhammer. 2001. Assessing consumer preferences for organic, eco-labeled, and regular apples. J. Agr. Resource Econ. 26:404-416.

Midwest Tree Fruit Management Handbook. ???? Jan. 2007. <http://www.ca.uky.edu/agc/pubs/ id/id93/ch_1.pdf $>$.

Mitchell, R.C. and R.T. Carson. 1989. Using surveys to value public goods: The contingent valuation method. Washington, DC: Resources for the future.

Murphy, J.J., P.G. Allen, T.H. Stevens, and D. Weatherhead. 2005. A meta analysis of hypothetical bias in stated preference valuation. Environ. Resour. Econ. 30:313-325.

Prokopy, R.J. and J. Avilla. 2003. Ecology and management of apple arthropod pests. Chapter
19, p. 489-519. In: Ferree, D.C. and I.J. Warrington (eds.). Apples: Botany, production, and uses. CABI, Cambridge, MA.

Reganold, J.P., J.D. Glover, P.K. Andrews, and H.R. Hinman. 2001. Sustainability of three apple production systems. Nature 410: 926-930.

Roosen, J., J.A. Fox, D.A. Hennessy, and A. Schreiber. 1998. Consumers' valuation of insecticide use restrictions: An application to apples. J. Agr. Resource Econ. 23:367-384.

Thompson, G.D. and J. Kidwell. 1998. Explaining the choice of organic produce: Cosmetic defects, prices, and consumer preferences. Amer. J. Agr. Econ. 80:277-287.

Wang, H. 2005. Organic apple price in response to crop size supplied to the market. PROGRESS REPORT - CSANR Organic Cropping Research for the Northwest. Oct. 2006. $<$ http://organic.tfrec.wsu.edu/OrganicCrop Research/ProgressReports05/WangPR05 ApplePrice.pdf>.

Williamson, S.M. and T.B. Sutton. 2000. Sooty blotch and flyspeck of apple: Etiology, biology, and control. Plant Dis. 84:714-724. 